\title{
O Serviço Social e o debate sobre tempo, história e memória
}

\section{Social Service and debate on time, history and memory}

\author{
Juliana Viana Ford ${ }^{a}$ \\ (D) https://orcid.org/0000-0001-9169-0569
}

Resumo: Este artigo é fruto de inquietações sobre o uso dos conceitos de tempo, história e memória na produção teórica do Serviço Social como categorias que desvendam a realidade e a profissão. Para tanto, parte das análises do historiador François Hartog sobre como a história é construída e pensada no Ocidente, no século XXI, e elege o pensamento de Walter Benjamin como referencial teórico para abordar história e memória articuladas aos princípios ético-políticos e teórico-metodológicos da profissão.

Palavras-chave: Tempo. História. Memória. Serviço Social.

\section{Introdução}

\begin{abstract}
This article is the result of concerns about the use of the concepts of time, history and memory in the theoretical production of Social Service as categories that reveal reality and the profession. For that, part of the analysis of the historian François Hartog on how history is constructed and thought in the West, in the XXI century, and elects the thought of Walter Benjamin as a theoretical reference to address history and memory articulated to ethico-political and theoreticalmethodological principles of the profession.
\end{abstract}

Keywords: Time. History. Memory. Social Work.

\section{"E o que foi feito é preciso Conhecer para melhor prosseguir \\ Falo assim sem tristeza, \\ Falo por acreditar Que é cobrando o que fomos \\ Que nós iremos crescer \\ Nós iremos crescer, \\ Outros outubros virão \\ Outras manhãs, plenas de sol e de luz."}

Milton Nascimento e Fernando Brant ${ }^{1}$

\footnotetext{
1 NASCIMENTO, M.; BRANT, F. O que foi feito deveras. In: NASCIMENTO, Milton. Clube da Esquina 2, 1978. 
$\mathrm{A}^{2}$ música brasileira é lugar de memória, de revisitar nossa trajetória, de nos reconectar com as sensações, as emoções e os sentidos do passado. A canção "O que foi feito devera", de autoria de Milton Nascimento e Fernando Brant, me fez pensar sobre as memórias que acessamos e sobre a importância de trazê-las conosco não apenas como lembranças do passado, como um arquivo morto das experiências. A memória é mais do que isso. Ela nos recoloca o presente a partir do passado e aponta para o futuro, para o devir. Em seus versos, a canção trata da necessidade de se voltar ao passado sem sentir saudades, retomando-o com atenção às possibilidades que se efetivaram como presente, tendo em vista o desafio de construir o futuro a partir das condições existentes. Memória e história se articulam na elaboração do tempo futuro, mas também na compreensão do presente, permitindo afirmar a dramaticidade deste início de século XXI.

Tal dramaticidade é entendida à luz da perspectiva teórico-metodológica do materialismo histórico e dialético no bojo das relações sociais capitalistas em sua fase madura. $O$ desenvolvimento das estruturas sociais forjadas para a produção e reprodução do capital teria atingido o seu ponto alto, e agora enfrenta uma crise que ameaça a sua própria existência. Essa crise ocorre em função de alterações na composição orgânica do capital, com a redução da quantidade de trabalho humano empregado no processo de produção de capital. Pois é na exploração do trabalho excedente, mais precisamente do tempo de trabalho humano excedente, que o capital enquanto relação social se torna possível. O capital depende do trabalho, ou seja, do não capital para se objetivar, mas é chegada uma fase do desenvolvimento das forças produtivas - impulsionado pela necessidade natural, porém incontrolável, do capital de se expandir - em que o trabalho morto - trabalho objetificado em matéria-prima e insumos para a produção de mercadorias - se sobrepõe ao trabalho vivo. Este é, portanto, um limite inerente à própria dinâmica capitalista e para o qual não se produziu uma solução definitiva. A dificuldade enfrentada pelo capitalismo para superar esse entrave fica evidente diante da lógica destrutiva assumida pelos processos sociais nas últimas décadas, que nos aproxima de uma nova barbárie.

Embora as guerras, a destruição dos recursos naturais em larga escala e de forma progressiva, o genocídio de populações inteiras, o ódio entre povos 
de diferentes culturas e outros horrores desses tempos sombrios expressem o oposto do que se entende por humanidade, a permanência das relações sociais que as produz se escora em uma ideia de futuro sem futuro, ou que se limita ao presente. Esse é o modo como o historiador francês François Hartog entende a questão da recente construção histórica e elaboração teórica no Ocidente. Seus estudos se concentram no desenvolvimento do conceito de presentismo: a perda de expectativas quanto ao futuro cria um movimento de simples manutenção das estruturas sociais, políticas, econômicas, culturais e ideológicas já conhecidas. O passado é abandonado, e com isso nos limitamos a conservar o presente. As sociedades ocidentais sob a influência da cultura europeia estariam vivendo sob um regime de historicidade em que as experiências do passado são evitadas, desprezadas devido às terríveis experiências produzidas no último século (os regimes fascistas e o Holocausto, por exemplo), e o futuro parece tão incerto, assombrado pelos fantasmas do passado, que as práticas sociais se concentram em atualizar as experiências do presente, em estender essas experiências ao máximo.

A reflexão de Hartog sobre a forma como a história é registrada (de maneira linear e numa perspectiva evolucionista) e legitimada como a história universal da humanidade, bem como sua interpretação do tempo presente em grande parte do mundo ocidental é um convite para pensar a memória nesse processo de perda de horizonte futuro. Ou seja, entendendo a sua potencialidade, a sua capacidade de alçar práticas cujo olhar para o passado reflete o futuro que se quer. O momento, para as forças de superação das relações sociais dominantes, é de reunir energias em busca de respostas para questões do presente. E essa busca, sinalizam alguns autores, passa pelo uso da memória não como lembrança apenas, mas como possibilidade de ressignificação das práticas sociais a partir das experiências que nos antecederam e que dão significado à forma contemporânea de existência social que se quer conhecer e ultrapassar.

Neste artigo são apontadas as transformações sociais oriundas do processo de avanço da modernidade e as mudanças na forma como o homem se relaciona com o tempo. Em contraponto, o pensamento de Walter Benjamin é abordado como inspiração para refletir a articulação entre tempo, história e memória, na perspectiva da construção de um futuro elaborado 
a partir de experiências passadas. A seguir, o uso da história e da memória como categorias teóricas pelo Serviço Social é apontada como uma forma de avançar na produção de uma crítica às relações sociais capitalistas, mas que necessita ser refletida tendo em vista a possibilidade de estarmos nos aproximando de interpretações da história e da memória que não se sustentam em seu caráter dialético. Por fim, destacamos a importância de se discutir esses conceitos no interior do Serviço Social e, assim, evitar as armadilhas do conservadorismo no âmbito da produção teórica da profissão.

\section{Tempo, história e memória: uma aproximação inicial}

História e memória são categorias cuja abordagem no meio acadêmico se torna ainda mais necessária em tempos de conhecimento fragmentado e desistoricizado. A valiosa contribuição de François Hartog a respeito do tema, e que fornece novo fôlego para estas discussões, está em se questionar qual é a concepção de história à qual nos referimos. Pois enquanto conceito, uma abstração da realidade, a história possui lugar, tempo, recortes de classe e de gênero. A história não é neutra dessas questões, e isso precisa ser observado em sua construção teórica. Rompendo com a perspectiva dominante de história submetida à noção de tempo dos relógios e calendários, um tempo alheio à humanidade e que a representa de forma reduzida e homogênea, o autor afirma que "o tempo da história vem a se decompor em uma multiplicidade de tempos parciais, locais ou específicos, já que não apenas cada processo, mas também cada prática que o historiador decide estudar estão dotados de uma temporalidade própria ou, ainda melhor, não são dela separáveis" (Hartog, 2013, p. 168-169). E conclui que as múltiplas temporalidades e efeitos produzidos por essas diferenças conferem a noção de contemporâneo e não contemporâneo em todos os níveis.

Essa compreensão antropológica da história está na base do pensamento de Hartog, entendendo-a nas relações entre passado, presente e futuro. A ordem do tempo varia conforme a ênfase é colocada no passado, no futuro ou no presente. $\mathrm{O}$ modo como diferentes formações sociais realizam a experiência do tempo produz o que o autor denomina regimes 
de historicidade. A história universal, aquela vivida pela Europa moderna e naturalizada pelos países do Ocidente como a medida da história, tem como característica a ênfase no futuro. É futuro-centrada. A ideia de progresso está por trás dessa construção da história, cujo sentido foi atribuído pela filosofia idealista. Porém esse sentido perde força na medida em que o século XX é feito de acontecimentos que vão na contramão do futuro. $\mathrm{O}$ progresso vinculado ao avanço da modernidade mostrou-se o combustível para grandes avanços em termos técnicos, científicos e de conhecimento, mas também para provocar guerras, destruição em massa, regimes fascistas, perseguições e morte de populações. Começam, então, a surgir críticas à ideia do processo de civilização entre os pensadores da história, as quais questionam o progresso como categoria universal.

O declínio da perspectiva futurista toma contornos mais definidos por volta dos anos 1970, quando houve o refluxo dos movimentos revolucionários no mundo, a crise da economia capitalista e a escalada do desemprego estrutural como sua consequência, bem como a dissolução do Estado de bem-estar social nos países em que essa experiência foi possível. O que se observa após a crise do futurismo é a expansão do presente. $O$ presente passou a ser a noção de tempo que mais interessa à humanidade nas últimas décadas. $\mathrm{O}$ passado, nesse contexto, é considerado obsoleto, e o futuro tornou-se motivo de preocupação, sendo temido, visto com desconfiança e sem muitas esperanças. Pois enquanto desconhecido, o futuro é a incerteza do amanhã, é a possibilidade de que as experiências catastróficas do passado, as quais tanto desprezamos, se repitam. As relações se voltam para o tempo presente, para a ampliação dessa dimensão, em detrimento das experiências do passado e da elaboração de um futuro. O presentismo, portanto, faz-se na ausência de expectativas sobre o devir e de referências ao antigo. $O$ presente é o passado e o futuro de que precisa. Valoriza o imediato. Hartog relaciona o presentismo à mercantilização da vida e seus efeitos.

Nessa progressiva invasão do horizonte por um presente cada vez mais inchado, hipertrofiado, é bem claro que o papel motriz foi desempenhado pelo desenvolvimento rápido e pelas exigências cada vez maiores de uma sociedade de consumo, na qual as inovações tecnológicas e a busca de benefícios cada vez 
mais rápidos tornam obsoletos as coisas e os homens, cada vez mais depressa. Produtividade, flexibilidade, mobilidade tornam-se as palavras-chave dos novos administradores. Se o tempo é, há muito, uma mercadoria, o consumo atual valoriza o efêmero. [...].

Esse tempo coincide também como o do desemprego em massa que as sociedades europeias começaram a sofrer nessa época. Para o desempregado, um tempo cotidiano, sem projetos possíveis, é um tempo sem futuro. Para esses "homens sem futuro", como os denominava Pierre Bourdieu, "o tempo parece se aniquilar", pois "o trabalho assalariado é o suporte, senão o princípio, da maior parte dos interesses, das expectativas, das exigências, das esperanças e dos investimentos do presente, assim como no futuro ou no passado que ele envolve. $O$ desemprego contribui fortemente para o confinamento no presente e para um presentismo, agora penoso e desesperado. (Hartog, 2015, p. 147-148)

A experiência do presente limitado em si mesmo, que não retorna ao passado nem almeja o futuro, e que é fruto do desenvolvimento do progresso e da ideia de modernidade é objeto da análise crítica do pensador alemão Walter Benjamin, tendo se dedicado entre 1920 e 1940, ano da sua morte, à elaboração de um conceito de história que se coloca na contracorrente do avanço do progresso e da ideia de que a humanidade se move em um tempo linear e homogêneo. Benjamin questiona a ruptura entre passado e presente ao desenvolver uma concepção de tempo que, "partindo do presente, traz o passado à atualidade do presente, o guarda, tomando por sua base a noção de Jetztzeit e lidando com o que ele denomina 'rememoração' (Eingedenken)" (Hartog, 1996). Em Sobre o conceito de história, afirma que como um relâmpago, cujo clarão não dura mais do que um instante, o passado se torna aparente, porém como imagem irrecuperável. Apreendê-lo significa apoderar-se de uma recordação que surge súbita e instantaneamente num momento de perigo. A ameaça consiste na possibilidade de nos transformarmos, e as nossas tradições, em instrumentos das classes dominantes. "Ao materialismo histórico interessa-lhe fixar uma imagem do passado tal como ela surge, inesperadamente, ao sujeito histórico no momento do perigo" (Benjamin, 2012, s/p).

Para o autor, lidar com o passado implica projetar-se ao futuro. 0 passado aponta para o futuro, que no momento é passado: olhando para um se 
enxerga o outro. O futuro é a realização das possibilidades apresentadas no passado, é a concretização do devir que existe como tempo passado. E quando afirma que o acesso ao passado só é possível por meio da recordação, Benjamin deixa claro o estreito laço entre tempo, história e memória. "O conceito de 'dialética' é, aqui, extraído por Benjamin da linguagem hegeliana-marxista: ele tenta dar conta da natureza de uma imagem 'salvadora' que se propõe à superação - Aufhebung - das contradições entre o passado e o presente, a teoria e a prática" (Löwy, 2005). Através do conceito de ruína o filósofo alemão não apenas expõe a sua compreensão dos processos envolvendo tempo, história e memória, como apresenta o caráter radical e utópico do seu ponto de vista sobre essas relações no século XX. Walter Benjamin é um crítico das transformações produzidas sob o avanço do capitalismo, o qual impulsiona e é impulsionado pelo desenvolvimento acentuado das forças produtivas. 0 aprimoramento das técnicas e dos instrumentos de produção assume nessa etapa da história da humanidade um ritmo acelerado, ditado pela necessidade cada vez maior de expansão dessa forma econômica, política, social, cultural e ideológica. Mas esse processo não ocorre sem a necessária transformação do homem, fonte do trabalho que dá substância ao capital, em sujeito subordinado à realização de interesses alheios aos seus reais interesses.

Pois o trabalho é a atividade na qual o homem movimenta a sua energia, a sua força de transformação, para modificar a natureza criando produtos com os quais satisfaz as próprias necessidades, transformando a si mesmo. "Atuando assim sobre a natureza externa e modificando-a, ao mesmo tempo modifica sua própria natureza. Desenvolve as potencialidades nela adormecidas e submete ao seu domínio o jogo das forças naturais" (Marx, 2011, p. 211). Atingida a fase das relações sociais capitalistas, aquela em que segundo Marx é abandonada a pré-história da humanidade, o domínio do homem sobre a natureza se submete ao domínio da forma social do capital. Uma forma de dominação impessoal, cuja raiz está nos processos sociais realizados sob o fenômeno da alienação promovida pelo fetiche da mercadoria. Este consiste no ocultamento do caráter social do trabalho e dos produtos que realiza sob a forma de mercadoria, de modo que esses produtos parecem figuras autônomas, com vida própria, independentes dos seus produtores. Não obstante, o homem sofre um processo inverso: na aparência, 
não se reconhece enquanto sujeito produtor de valores; a sua capacidade de transformação da natureza lhe foi ocultada, o que o assemelha às coisas, aos objetos inanimados (Ibidem, p. 94).

Os homens se formam e são formados na e pelas relações sociais capitalistas, submetendo-se a uma forma histórica de existência que desconsidera suas identidades, neutraliza seus afetos, suas emoções, e os homogeniza, padroniza seus comportamentos, seus corpos, seus gostos, tornando-os úteis e funcionais à reprodução dessas relações. Essas transformações avançam também sobre o espaço físico, convertendo "os espaços-tempos em formas lisas, equivalentes a si mesmas” (Abreu, 2016, p. 48). Nesse cenário de pleno desenvolvimento do progresso, da modernidade e da civilização, Walter Benjamin pensa as suas ruínas. Ou seja, os vestígios de produtos e relações anteriores às que se colocam na atualidade, portanto, pouco acabadas do ponto de vista da modernidade, e que ressignificados podem trazer novos sentidos às experiências. Para o autor, "Uma miséria totalmente nova se abateu sobre o homem com esse desenvolvimento monstruoso da técnica" (Benjamin, 1986, p. 95). Tal miséria se expressa como a produção de um patrimônio cultural que não se vincula aos seus produtores. A pobreza das experiências não é particular, mas uma pobreza da humanidade e que configura uma espécie de nova barbárie tomada como um conceito positivo, em que o vazio das experiências na modernidade serve de mola propulsora para os homens. Trata-se de entender a ausência como condição e/ou motivação para a criação de algo que nasce como novo, para o estímulo à criatividade e à invenção, de modo a produzir formas autênticas de estar no mundo. Conforme afirma Abreu (2016, p. 48), “A crítica de Benjamin ao capitalismo moderno é crucial para os estudos de memória social, uma vez que reabilita outras formas temporais".

No entanto, assim como diversas ideias foram e são disputadas pelas classes antagônicas, a memória é uma categoria abordada não apenas pelos críticos das relações sociais capitalistas. Hartog cita Pierre Nora ao afirmar que a aceleração do tempo presente cria múltiplas memórias coletivas não relacionadas, que são fragmentadas, bem como a ruptura com o passado, o que quer dizer o próprio desaparecimento da memória. Nesse sentido, a memória tem sido tão mencionada na atualidade exatamente porque já não 
existe mais enquanto conexão entre passado e futuro. Hartog compara as formas antiga e atual de elaboração da memória.

"Nossa" memória não é mais aquela, ela que agora só é "História, vestígio e triagem". Preocupada em fazer memória de tudo, ela é apaixonadamente arquivística, contribuindo a essa cotidiana historicização do presente, já observada. Inteiramente psicologizada, a memória tornou-se um assunto privado, que produz uma nova economia de "identidade do eu". "Pertence a mim [doravante] a atividade de lembrar-me e sou eu que me lembro." Assim, ser "judeu é lembrar-se de ser, mas essa lembrança irrecusável, uma vez interiorizada, exige pouco a pouco uma dedicação integral. Memória de quê? No limite, memória da memória". Enfim, essa memória opera a partir de uma relação com o passado na qual sobrepuja a descontinuidade. 0 passado não está mais "no mesmo plano". Por consequência, fomos "de uma história que se procurava na continuidade de uma memória a uma memória que se projeta na descontinuidade de uma história". Tal como se define hoje em dia, a memória "não é mais o que se deve reter do passado para preparar o futuro que se quer; ela é o que se faz com que o presente seja presente para si mesmo". Ela é um instrumento presentista. (Hartog, 2015, p. 162-163)

Todavia, como o próprio Hartog destaca, o presentismo e a quebra da relação entre passado e futuro no regime moderno são compreendidos no campo da experiência do tempo desenvolvida na Europa. E como se sabe, a forma desigual e heterogênea como as relações capitalistas e o processo civilizador avançaram do centro europeu para outras regiões do globo é condição para que as experiências, inclusive do tempo, nessas regiões tenham sido construídas sob uma perspectiva diferente da que se conhece e admite como dominante. Formas mais orgânicas e autênticas de produção e de estabelecimento das relações sociais podem ser observadas junto a povos originários, cujas tradições concebidas pelos antepassados são mantidas ainda hoje por serem dotadas de um sentido que os aproxima mais da satisfação das suas reais necessidades do que o sentido mercadológico com o qual as práticas sociais são reproduzidas no centro do capitalismo. Também os movimentos sociais fincados nos espaços urbanos e que questionam o uso e acesso a estes querem retomá-los e atribuir-lhes um outro sentido, 
diferente do que é conferido à cidade na modernidade. Essas formas de luta populares dotadas de autenticidade revolucionária que se contrapõem ao modo de ser produzido e reproduzido na esteira do processo histórico de consolidação da forma moderna das relações sociais tem na memória uma ferramenta valiosa para enfrentar e resistir aos avanços das forças conservadoras de dominação social.

A expansão do capital, enquanto relação social, pelo mundo desde o fim do século XVIII e início do XIX, é um processo inconteste, mas que se dá no âmbito das particularidades históricas, sociais, políticas, econômicas e culturais de cada região. Significa que mesmo que o capitalismo tenha ampliado os seus domínios e se consolidado diante de tradições locais, não é possível afirmar que estas foram completamente esquecidas, eliminadas da memória dos indivíduos e grupos. Também que não existam ou que não estão sendo produzidas estratégias de resistência a essa forma de dominação, baseadas na autenticidade das experiências populares e comunitárias. Cabe, então, mais uma vez, ressaltar o brilhantismo da visão de Walter Benjamin, autor que nos inspira a pensar a história e a memória nestes tempos de barbárie.

Benjamin desenvolve um conceito dialético de história em que passado e futuro estão íntima e necessariamente relacionados como possibilidade de construção do novo, invocada pela memória. Em tempos de fixação do presente, esvaziamento das experiências humanas e do redesenho de uma nova barbárie, esse pensamento ajuda a identificar outros caminhos às forças revolucionárias e ao debate da luta anticapitalista. E mais: tem a lucidez e a maturidade para examinar o pensamento crítico e apontar seus limites e dificuldades. Interpreta, por exemplo, como o passado da luta de classes é frequentemente reduzido, até mesmo pelos historiadores vinculados à tradição marxista, como o eterno triunfo da classe dominante sobre a classe dominada. Mas olhando para essa história evolucionista ao lado dos "vencidos", os novos combates travados pelos oprimidos colocam em questão a dominação do presente e as vitórias do passado.

As lutas atuais colocam em questão as vitórias históricas dos opressores, porque minam a legitimidade do poder das classes dominantes, antigas e atuais. Benjamin se opõe, nesse caso, implicitamente, a uma certa concepção 
evolucionista do marxismo - já presente em algumas passagens de Marx (entre outras, no Manifesto comunista e nos artigos sobre a Índia dos anos 1850) - que justifica as vitórias da burguesia no passado pelas leis da história, a necessidade de desenvolver as forças produtivas ou a imaturidade das condições para a emancipação social.

A relação entre hoje e ontem não é unilateral: em um processo eminentemente dialético, o presente ilumina o passado, e o passado iluminado torna-se uma força no presente. (Löwy, 2005, s/p)

\section{Um debate necessário ao Serviço Social?}

O Serviço Social é uma profissão que surge na esteira dos processos de consolidação da ordem do capital, inicialmente sob forte influência da Igreja católica, assumindo em sua prática um viés conservador de controle e integração da classe trabalhadora que beneficia os interesses da acumulação capitalista. Na década de 1960, o Serviço Social brasileiro inicia a construção das bases teórico-metodológicas e ético-políticas que possibilitaram um salto à profissão, no sentido de tentar romper com essa herança conservadora a partir do entendimento da luta de classes. O movimento de contestação dos fundamentos técnico-operativos e da corrente de pensamento que orientavam o trabalho dos assistentes sociais à época começou a ser gestado em meio a uma situação de crise e efervescência política na América Latina, a qual foi marcada pela intervenção estrangeira nos assuntos do país que subsidiou o golpe de 1964. As reações ao regime autocrático foram duramente reprimidas durante os anos de ditadura militar, não tendo impedido, porém, que o Serviço Social se aproximasse de fontes das ciências sociais e, sobretudo, da tradição marxista, num momento em que a profissão se expandia e buscava a tecnificação dos seus instrumentos de intervenção sob a lógica do progresso e da necessidade de modernização do país. Esse contexto, ao contrário, possibilitou tal discussão nos espaços universitários e junto aos movimentos sociais e sindicais (Netto, 2008, p. 257), o que contribuiu para lançá-lo a um outro patamar: o da compreensão da realidade na qual atuam os assistentes sociais sob uma perspectiva que questiona as suas estruturas de reprodução. 
Desde que a categoria profissional passou a se posicionar politicamente pela realização dos interesses e do projeto societário das classes trabalhadoras, intencionando a ruptura com o conservadorismo, num esforço para redirecionar a sua prática coletiva contra os avanços do capitalismo e a favor das camadas da classe trabalhadora, se reconhece a necessidade de criar uma nova identidade para os assistentes sociais que seja compatível com esse posicionamento. $\mathrm{O}$ que se configura tarefa de extrema complexidade, haja vista a capacidade de atualização do conservadorismo conforme os processos de reprodução da sociabilidade do capital se desenvolvem. Nesse sentido, uma importante arma do Serviço Social contra as correntes do pensamento que naturalizam essa ordem social e/ou que desqualificam o pensamento crítico revolucionário - positivismo, estruturalismo, funcionalismo, pós-moderno - está, justamente, no domínio da teoria social crítica, de reflexões teóricas que de fato contribuam para a necessária desconstrução e reconstrução das ideias e do fazer do assistente social comprometido com a realização do projeto profissional. Assim sendo, é preciso estar atento para qual conhecimento tem contribuído com a formação dos assistentes sociais e de que forma. Nas palavras de Iamamoto (2013, p. 43), "Questiona-se, inclusive, que tipo de orientação teórico-metodológica deve informar a prática e como esta pode ser repensada a serviço da produção de conhecimentos voltados para os interesses dos 'setores populares' e de sua organização autônoma".

Deve-se, portanto, enfatizar a necessidade de pensar como o Serviço Social se relaciona com a história. De questionar qual é o conceito de história que atravessa as discussões sobre a realidade social e sobre a própria profissão no seu interior, haja vista ser essa uma dimensão fundamental da construção do seu ponto de vista teórico. A importância de entender os processos sociais e suas manifestações fenomênicas percebidas no cotidiano é constantemente afirmada e reafirmada pela produção intelectual do Serviço Social. O caráter histórico das relações sociais, da produção material e espiritual a partir de condições primeiramente objetivas, mas também culturais, políticas e ideológicas historicamente determinadas, as quais sofrem modificações dando origem a formações sociais distintas, foi apresentado à profissão através do estudo do método marxiano de aproximação 
da realidade. Essa concepção encontra ressonância dentro da categoria de assistentes sociais, sendo essencial ao debate sobre os fundamentos do Serviço Social. Segundo Iamamoto (2015, p. 203):

(...) a história é a fonte de nossos problemas e a chave de suas soluções. Dessa maneira, a ruptura com o profissionalismo estreito, a implosão do "estritamente profissional", a abertura para mais longe - para o amplo horizonte do movimento da sociedade - é que torna possivel iluminar as próprias particularidades do Serviço Social, apreendendo-o na trama de relações que explicam sua gênese, seu desenvolvimento, seus limites e possibilidades; trama essa que condiciona o âmbito de alternativas que se apresentam aos seus sujeitos profissionais em cada momento conjuntural. (grifo do autor)

Ocorre que a história, enquanto um conhecimento produzido por homens sujeitos às condições objetivas e subjetivas de sua época, precisa ser pensada enquanto tal pelo Serviço Social, de modo a se fazer escolhas mais qualificadas das fontes que subsidiam os debates internos. Escolhas coerentes com o arcabouço teórico-metodológico e com o posicionamento ético-político assumido pela profissão. Trata-se, portanto, de negar a perspectiva histórica eurocêntrica, que se coloca como a única possível e que é pensada linearmente, considerando a ideia de progresso, o que cria as noções de desenvolvimento e de atraso entre os países, suas regiões e mesmo entre as populações internas. Noções estreitamente relacionadas à questão econômica, ao predomínio da dimensão econômica sobre as demais dimensões da vida social, geradora de profunda desigualdade e competitividade. Conforme mencionou Yolanda Guerra durante o I Seminário Nacional de Fundamentos do Serviço Social, ocorrido em 6 de novembro de 2017 na Universidade Federal do Rio de Janeiro, cada época tem suas tendências e projeto hegemônico. Faz parte do projeto da classe econômica, política, ideológica e culturalmente dominante produzir e difundir as suas ideias como as ideias deste tempo histórico, naturalizando-o. E, na medida em que não se atenta devidamente para essa questão, a produção intelectual comprometida com a crítica dessas relações corre o risco de abraçar ideias que não são coerentes com a perspectiva teórica e política que defende. 
Como abordar as particularidades da formação socioeconômica do país em relação aos avanços produzidos pelo capitalismo em regiões onde este atingiu a sua maturidade, considerando a história como uma marcha constante para o futuro, na qual o passado não tem valor, é ultrapassado? Como entender os processos da sociedade brasileira utilizando um conceito de história que desconsidera a importância desses processos, pois só reconhece como legítimo o olhar do homem branco, europeu, colonizador sobre as transformações ocorridas no globo ao longo do desenvolvimento da humanidade? Em face dessa discussão, voltamos à fala de Yolanda Guerra no referido evento, no qual indaga: o que é história para o Serviço Social? Com qual concepção de história o Serviço Social pensa a profissão? A história dá protagonismo ao sujeito, mas quem é esse sujeito? Essas são questões que nos provocam a fazer a defensa pela escolha de um conceito dialético de história, que critique a linearidade da perspectiva eurocêntrica de história e a aceleração do presente como fim em si mesmo. Esse conceito tem no filósofo alemão Walter Benjamin um representante que nos inspira com suas reflexões sobre tempo, história e memória.

A memória é outra categoria cuja relevância para a compreensão das relações sociais se torna mais evidente a partir da crise do paradigma eurocêntrico da história e que, portanto, deve ser abordada mais atentamente pelo Serviço Social. Isso porque a memória está nas discussões realizadas pela profissão que fazem uso da história oral como metodologia de investigação. Expor os relatos dos sujeitos de certa pesquisa a fim de demonstrar, por meio de sua história de vida, as relações entre a parte e o todo, o universal e o particular, é uma prática que ao ser realizada no interior da produção teórica do Serviço Social destaca que somos feitos de experiências, de relações com o outro, bem como coloca em evidência a riqueza da narrativa dessas experiências contadas a partir do ponto de vista dos indivíduos e dos grupos que as vivenciam, mas que não têm reconhecido o seu valor no contexto da predominância dos discursos científicos. A contribuição de Moljo (2000, p. 18) acerca do assunto nos faz pensar na potência dessa metodologia para o Serviço Social:

Consideramos que o trabalho com este tipo de metodologia poderia enriquecer as investigações em nosso campo disciplinar, uma vez que abre um novo 
olhar e uma nova perspectiva a partir da intervenção profissional. Tendo em mente que temos a possibilidade diária e concreta que poucas profissões tem de trabalhar com sujeitos históricos em suas próprias vidas.

Observa-se que o Serviço Social tem se apropriado da noção de memória para discutir a profissão na tentativa de reconstruir sua trajetória histórica e, assim, reafirmar os compromissos políticos do presente, alinhando-os com a prática profissional. A tese de doutorado de Elisabete Terezinha Silva Rosa expressa esse movimento de aproximação e domínio de técnicas e instrumentos de pesquisa que permitem abordar a profissão do ponto de vista dos sujeitos que a constroem historicamente através da memória. No caso específico, a autora investiga os desafios e avanços que fizeram parte do processo de constituição do Serviço Social entre 1959 e 2009, recuperando as experiências de Nabuco Kameyama.

Partimos da hipótese de que história é frequentemente buscada, mas a forma como é recuperada pode estar plena de opacidade, ou seja, pode ocultar a realidade das coisas, de tal modo que essa só pode ser reconhecida quando se transpõe a aparência. Da mesma forma, a história do Serviço Social contém opacidades, e é preciso conhecê-la nas entrelinhas e decodificar os diversos contextos social, econômico, cultural e político, no qual esteve e está inserido, e o descortinar de nuances dessa história nos possibilitará compreender melhor o contexto atual e o porvir, e revelar um instrumento de poder importante para solidificar as bases históricas do projeto profissional. (Rosa, 2016, p. 49)

Essa movimentação que o Serviço Social tem produzido em torno da abordagem da história e da memória numa perspectiva que busca identificar as relações entre o todo e a parte, sem se descuidar de apreender as conexões entre passado, presente e futuro, aponta para a preocupação dos pesquisadores da área de investir em metodologias que contribuam para se pensar a realidade de forma crítica, desvelando a sua essência e propondo ações coerentes com esse ponto de vista que expressa um posicionamento político aproximado das classes exploradas. Os estudos de Martinelli a 
respeito da identidade e da pesquisa qualitativa no Serviço Social confirmam a relevância da temática. Nesse sentido é que afirmamos a necessidade de discutir internamente esses conceitos, tendo em vista a disputa ideológica envolvendo história e memória.

\section{Considerações finais}

A relação do Serviço Social com a história, utilizando-a para entender a realidade na sua complexidade, para ir além da aparência dos fenômenos e percebê-los na sua essência, é indispensável à formação e ao desenvolvimento de profissionais críticos e questionadores. Está alicerçada no materialismo dialético, fundamental ao pensamento de Marx. Esse ponto de vista assumido pelo Serviço Social na escolha do seu referencial teórico-metodológico vai de encontro à forma hegemônica como a história é entendida entre os países cultural e intelectualmente submetidos às ideias da Europa Ocidental, ou simplesmente dos países civilizados. Uma história universal linear e progressiva se sobrepõe a outras formas de narrá-la. Identificar essa ameaça ao pensamento crítico é de fundamental importância para que se possa ultrapassá-lo. Em outras palavras, mais do que comprometer-se com o desenvolvimento de uma análise histórica da realidade social e da própria profissão, o Serviço Social deve atentar-se sobre como fazê-la. Deve se perguntar se a história que é acessada para discutir os processos sociais consegue dar conta de percebê-lo sob uma perspectiva de não subordinação de um povo sobre o outro, ou de uma nação sobre outra economicamente menos desenvolvida. Se esse referencial teórico questiona esses parâmetros culturais, sociais e econômicos de classificação dos atores sociais e se apresenta o ponto de vista dos que tiveram os seus costumes e as suas tradições ressignificados sob a lógica do avanço da civilização. Sem discutir tais questões, a história se mantém coerente com o movimento de reprodução do status quo, o que compromete a intencionalidade por trás da produção intelectual do Serviço Social.

A discussão sobre tempo, história e memória pelo Serviço Social tende a resultar relevante contribuição à forma como a profissão enxerga 
a realidade, pois trata-se de um esforço no sentido de qualificar seus fundamentos teóricos, negando o conhecimento acrítico e se munindo de interpretações que possibilitem alcançar um outro patamar na discussão sobre a historicidade das relações sociais. Enxergar a memória como um campo de possibilidades para a prática revolucionária, o qual o Serviço Social pode entender melhor, significa criar nova frente para a pesquisa em Serviço Social em que a memória não aparece como coadjuvante no processo de investigação da realidade, mas como instituto que aproxima os sujeitos da luta anticapitalista.

\section{Referências}

ABREU, R. Memória social: itinerários poético-conceituais. Revista Morpheus, Rio de Janeiro, v. 9, n. 15, 2016. Edição especial.

BENJAMIN, W. Sobre o conceito da história. In: . O anjo da história. Belo Horizonte: Autêntica Editora, 2012.

Experiência e pobreza. In: Documentos de cultura, documentos de barbárie: escritos escolhidos. São Paulo: Cultrix; Editora da Universidade de São Paulo, 1986. p. 195-198.

HARTOG, F. Experiências do tempo: da história universal à história global? História, Histórias, Brasília, v. 1, n. 1, 2013. Disponível em: <http://periodicos.unb.br/index.php/ hh/issue/view/837>. Acesso em: 13 set. 2017.

Time, History and Writing of History: the order of time. Conferência pronunciada em Stocolmo em 1996 (KVHAA Konferenser 37: 95-113 Stockholm 1996). Disponível em: <https://pos.historia.ufg.br/up/113/o/Fran\%C3\%A7ois_Hartog_-_Regime_de_Historicidade_\%281\%29.pdf>. Acesso em: 23 ago. 2017.

Regimes de historicidade: presentismo e experiências do tempo. Belo Horizonte: Autêntica Editora, 2015.

IAMAMOTO, M. V. Renovação e conservadorismo no Serviço Social: ensaios críticos. São Paulo: Cortez, 2013.

O serviço social na contemporaneidade: trabalho e formação profissional. São Paulo: Cortez, 2015.

LÖWY, M. Walter Benjamin: aviso de incêndio. Uma leitura das teses "Sobre o conceito de história". São Paulo: Boitempo, 2005.

MARX, K. O capital: crítica da economia política. 29. ed. Rio de Janeiro: Civilização Brasileira, 2011. Livro I, v. 1. 
MOLJO, C. La historia oral como posibilidad de reconstrucción histórica, su relación con el trabajo social. Centro Português de Investigação em História e Trabalho Social, Portugal, v. 16, n.1, p. 1-29, 1999. Disponível em: <http://www.cpihts.com/2003_07.31/hist_oral. htm>. Acesso em: 5 set. 2017.

NETTO, J. P. Ditadura e Serviço Social: uma análise do serviço social no Brasil pós-64. São Paulo: Cortez, 2008.

ROSA, E. T. S. História e memória em Serviço Social: a trajetória profissional de Nabuco Kameyama. Tese (doutorado) — PUC, São Paulo, 2016. Disponível em: <https://sapientia. pucsp.br/handle/handle/19096>. Acesso em: 17 out. 2017.

\section{Sobre a autora}

Juliana Viana Ford - Professora substituta; mestre em Serviço Social, Universidade Federal do Rio de Janeiro.

E-mail: ju_ford@hotmail.com 